\title{
Batman mera vejetasyonlarının bazı özellikleri
}

\section{Some characters of rangeland vegetation in Batman province}

\author{
Seyithan SEYDOŞOǦLU ${ }^{1 *}$, Kağan KÖKTEN² \\ ${ }^{1}$ Siirt Üniversitesi Ziraat Fakültesi Tarla Bitkileri Bölümü, Siirt \\ ${ }^{2}$ Bingöl Üniversitesi Ziraat Fakültesi Tarla Bitkileri Bölümü, Bingöl
}

\section{To cite this article:}

Seydoşoğlu, S. \& Kökten, K. (2019). Batman mera vejetasyonlarının bazı özellikleri. Harran Tarım ve Gıda Bilimleri Dergisi, 23(1): 60-68.

DOI:

10.29050/harranziraat.424007

Address for Correspondence: Seyithan SEYDOŞOĞLU e-mail:

seyithanseydosoglu@siirt.edu.tr

Received Date:

16.05.2018

Accepted Date:

12.10.2018 öz

Batman ili meralarının bazı vejetasyon özelliklerinin belirlenmesi amacı ile 2016 yılı NisanHaziran aylarında yapılan bu çalışmada modifiye edilmiş tekerlekli lup (halka) metodu kullanılmıştır. Vejetasyon etüdü 33 durakta yapılarak yürütülmüştür. Araştırma sonucunda 52 tanesi baklagil, 35 tanesi buğdaygil ve 115 tanesi de diğer familyalara ait türler olmak üzere toplam 202 tür tespit edilirken, bu türlerin 13 tanesi çoğalıcı, 12 tanesi azalıcı ve 177 tanesi de istilacı tür olarak belirlenmiştir. Araştırma sahasında ortalama bitki ile kaplı alan oranı \%81.06, baklagillerin botanik kompozisyondaki ortalama oranı \%33.71, buğdaygillerin oranı \%27.27 ve diğer familyaların oranı \%39.02 olarak tespit edilmiştir. Botanik kompozisyon farklı kalite derecesine sahip türler bakımından değerlendirildiğinde ise; azalıcıların oranı \%3.15, çoğalıcıların oranı \%6.59 ve istilacı türlerin oranı da \%90.26 olarak belirlenmiştir. Araştırmadan elde edilen sonuçlara göre çalışılan tüm meraların "Zayıf"mera durumu sınıfına girmiştir. Mera sağlığı açısından yapılan sınıflamada ise tüm meraların "Sağlıkıı"olduğu tespit edilmiştir. Tüm bu sonuçlar dikkate alındığında, Batman ili meralarının derhal ıslah programına dâhil edilmeye intiyaç duymaktadır.

Anahtar Kelimeler: Mera durumu, İstilaci türler, Vejetasyon etüdü, Lup metodu

\section{ABSTRACT}

This study was conducted to determine some vegetation characters of rangelands in Batman province during the period of april-june in 2016. In the study, modified wheel point method with loop was used. Vegetation study was carried out in 33 station. Totally 202 plant species determined in the study area were categorized in 3 groups: i) 35 species were in family of grasses, ii) 52 species were in leguminosae, and iii) 115 species were in the group of other families. These plant species were also divided into 3 different successional groups: i) 12 species were decreasers, ii) 13 species were increasers, and iii) 177 species were invaders. In the study area, plant coverage rate was $81.06 \%$, average rate of legumes, grasses and other families in the botanical composition were found as $33.71 \%, 27.27 \%$ and $39.02 \%$ respectively. The results of the study showed that all of rangeland are "Poor" condition classes. On the other hand, all of rangeland stations were found as "Healthy" in health categories.

Key Words: Rangeland condition, Invader species, Vegetation survey, Loop method

\section{Giriş}

Türkiye'de çayır mera alanları Cumhuriyetin ilk yıllarına göre $\% 75$, son 60 yıla göre ise $\% 62$ oranında azalmıştır. Bu alanların azalmasına rağmen hala kaba yem ihtiyacımızın $1 / 3^{\prime}$ ü bu alanlardan karşılanmaktadır. Gelişmiş ülkelerde kaba yemin hem çayır mera alanlarından hem de yem bitkilerinden karşılanan oranı oldukça yüksektir. Batı Avrupa'da süt sığırlarının enerji ihtiyaçlarının \% 50'si çayır ve meralardan, \%25'i kuru ot ve silajdan, $\% 25$ 'i de kesif yemlerden karşılanmaktadır (Gür ve Altın, 2015). Ayrıca ABD 
süt sığırlarının beslenmesinde çayır mera otlarının payı \%61.2, koyun ve keçilerin beslenmesinde ise \%91.1'dir (Açıkgöz, 2001). Bu oranlar sağlıklı, ekonomik ve sürdürülebilir bir hayvancılıkta çayır ve meraların vaz geçilmez kaynaklar olduğunu ortaya koymaktadır. Çayır meralardan faydalanırken gereken özen gösterilmemiştir. Bu alanlar; erken, ağır ve düzensiz otlatılarak verim potansiyellerini kaybettikleri gibi florastik kompozisyonları da değişime uğramıştır. Bunun sonucunda, ot kaliteleri düştüğü gibi toprak özellikleri değişime uğramıştır (Gür ve Altın, 2015).

Türkiye İstatistik Kurumu verilerine göre yurdumuzda 13.2 milyon ha mera (toplam çayırmera alanı 14,6 milyon ha) bulunmaktadır. Bu alanın çoğu uzun ya da kısa süreli kuraklıkların hüküm sürdüğü Türkiye'nin iç kesimlerinde yer alırlar. Doğu, Orta ve Güneydoğu Anadolu Bölgeleri toplam 10.3 milyon ha mera alanı ile ülke toplam meralarının \%78'ine (yaklaşık 4/5) sahiptir (Anonim 2018a). Batman ili mera alanı 71.464 ha alandan oluşmaktadır. Mera alanlarının \%98'i Merkez, Beşiri ve Kozluk'ta yer almaktadır (Anonim, 2018b).

Alay ve ark. (2016)'nın Sinop meralarında yapılan bir vejetasyon araştırmasında, 28 tanesi baklagil, 27 tanesi buğdaygil, 79 tanesinin de diğer familya bitkilerine ait olduğunu tespit etmişlerdir. Tespit edilen türlerin botanik kompozisyondaki baklagillerin oranı \%20.9, buğdaygillerin oranı \%20.1 ve diğer familya bitkileri oranı ise \%59.0 olduğunu rapor etmişlerdir.

Seydoşoğlu ve ark. (2015a)'nın Diyarbakır meralarında yapılan bir çalışmada 10 bitki familyasının 27 farklı cinsinden 35 bitki türünün tespiti yapılmıştır. İncelenen meralarda bitki ile kaplılık oranlarının \% 26.60-60.36, botanik kompozisyondaki buğdaygillerin oranının \%27.8137.45, baklagillerin oranının \% 8.67-39.31, diğer familya bitkilerinin oranının ise \% 23.24-59.16 arasında değiştiğini bildirmişlerdir.

Bu kapsamda ülkemizin birçok ilinde yapılan çalışmaların devamı olarak Batman ili meralarının bazı vejetasyon özelliklerinin belirlenerek, gerek ıslah çalışmaları, gerekse hayvan baskısı ve iklim gibi faktörlerin etkisiyle zaman içinde mera vejetasyonunda meydana gelebilecek değişimlerin izlenmesine olanak sağlayacak bir alt yapının oluşturulması hedeflenmiştir.

\section{Materyal ve Metot}

Batman İli Güneydoğu Anadolu Bölgesi'nin Dicle Bölümünde 41 derece 10 dakika ve 41 derece 40 dakika doğu boylamları ile 38 derece 40 dakika ve 37 derece 50 dakika kuzey enlemleri arasında yer almaktadır. Bu çalışma Batman ili sınırları içerisinde yer alan 33 köyün kadimden beri tüm köy halkına açık ve serbest otlatma yapılan doğal meralarında (Şekil 1); 2016 yılı Nisan-Haziran aylarında yürütülmüştür. Bu meraların 7'si Merkez (Akça, Binatlı, Oymataş, Kayabağı, Çarıklı,Balpınar, Yolağzı), 15’i Beşiri ilçesine bağlı (Yontukyazı, Tepecik, Değirmenüstü, Ayrancı, Yalınkavak, Yazıhan, Asmadere, Yeşilova, Avcılar, Eskihamur, Merkez, Beyçayırı, Uğurca, Kuyubaşı, Deveboynu), 8'i Kozluk ilçesine bağı (Yeniçağlar, Karpuzlu, Kavakdibi, Yapaklı, Ulaşlı, Kahveci, Arıkaya, Uzunçayır), 2'si Hasankeyf İlçesine bağlı (Merkez, Üçyol) ve 1'i Gercüş ilçesine bağlı (Gürbüs) köylerde bulunan meralardır.

Çalışmada mera duraklarına ait bazı özellikler Çizelge 1'de belirtilmiştir. Çizelgede de görüldüğü gibi, meraların rakımları 532-905 m arasında değişmiştir. Meraların köye olan uzaklıkları 0.1-2.2 $\mathrm{km}$ arasında değişmektedir.

Meraların 12 tanesi hafif (\%2-5) ve 21 tanesi orta (\%6-11) eğimli olarak tespit edilmiştir. Meraların otlatma derecesine bakıldığında 18 tanesinin çok yoğun, 15 tanesinin de yoğun olarak otlatıldı̆ı belirlenmiştir. Tüm meraların erozyon oranları hafif (=>2 ile $<5$ ton/ha/yıl) ve orta $(=>5$ ile $<10$ ton/ha/yıl) arasında değiştiği belirlenmiştir. Meraların tümünde toprak derinliğinin sığ (20-49) olduğu belirlenmiştir (Anonim, 2005). 


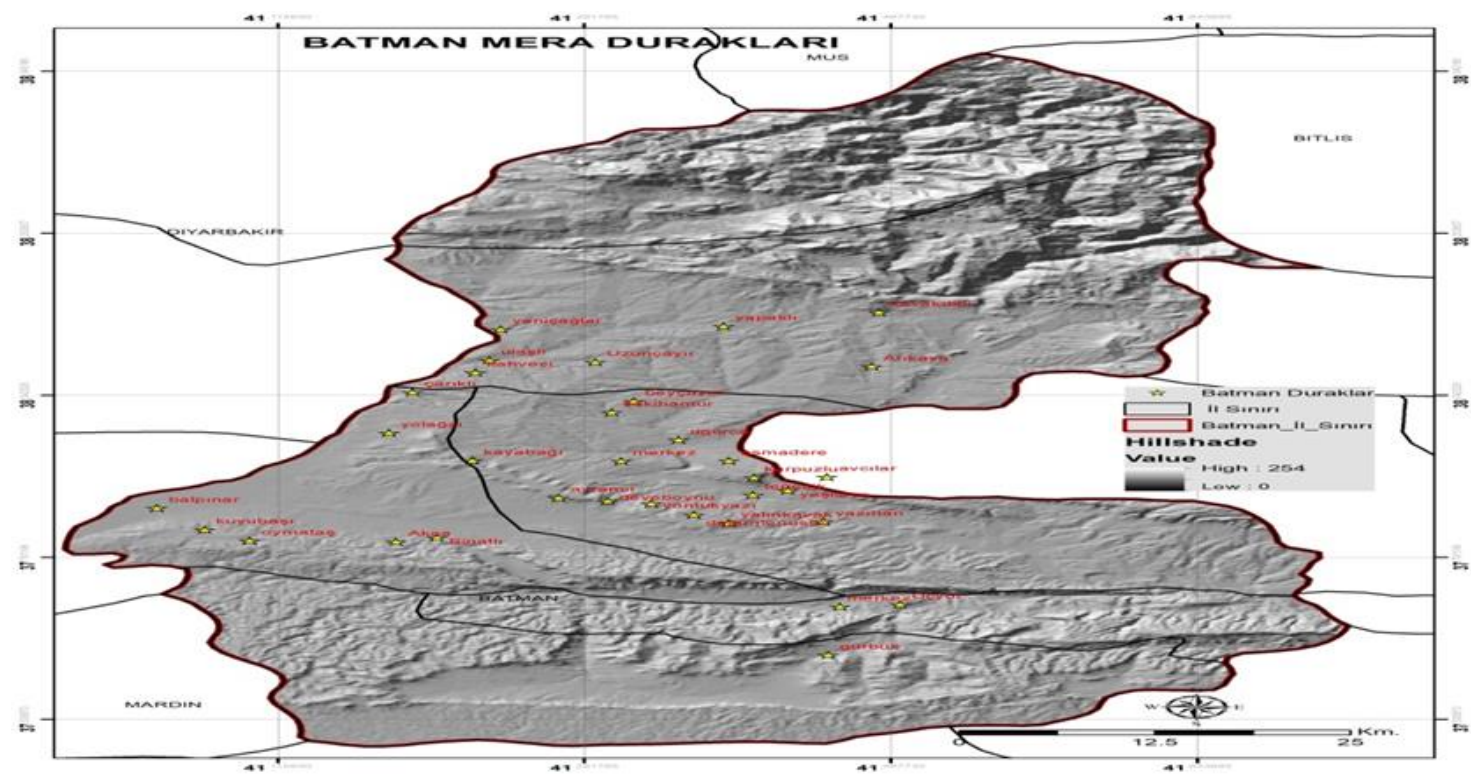

Şekil 1: Vejetasyon etüdü yapılan duraklar

Figure 1. Vegetation survey stations

Çizelge 1. Vejetasyon etüdü yapılan meraların coğrafi özellikleri ve otlatma dereceleri Table 1. Geographical characteristics and grazing levels of studied rangelands

\begin{tabular}{|c|c|c|c|c|c|c|}
\hline Rangeland name & Altitude & $\begin{array}{c}\text { Köye } \\
\text { uzaklık } \\
\text { (km) } \\
\text { Distance } \\
\text { from } \\
\text { Village } \\
\text { (km) }\end{array}$ & Slope (\%) & $\begin{array}{l}\text { Otlatma } \\
\text { derecesi }\end{array}$ & $\begin{array}{l}\text { Erozyon oranı } \\
\text { (ton/ha/yıl) } \\
\text { Erosion rate } \\
\text { (ton/ha/year) }\end{array}$ & $\begin{array}{c}\text { Toprak derinliği } \\
\text { Soil depth }\end{array}$ \\
\hline Yontukyazı & 815 & 0.5 & Orta (6-11) & Yoğun & Orta $=>5$ ile $<10$ & Sığ (20-49) \\
\hline Tepecik & 534 & 1.0 & Orta (6-11) & Yoğun & Orta $=>5$ ile $<10$ & Sığ (20-49) \\
\hline Değirmenüstü & 851 & 0.6 & Orta (6-11) & Yoğun & Hafif $=>2$ ile $<5$ & Sığ (20-49) \\
\hline Ayrancl & 844 & 1.2 & Hafif (2-5) & Çok yoğun & Hafif $=>2$ ile $<5$ & Sığ (20-49) \\
\hline Akça & 734 & 0.7 & Hafif (2-5) & Yoğun & Orta $=>5$ ile $<10$ & Sığ (20-49) \\
\hline Binatlı & 702 & 1.5 & Hafif (2-5) & Çok yoğun & Orta $=>5$ ile $<10$ & Sığ (20-49) \\
\hline Oymataş & 648 & 1.8 & Orta (6-11) & Çok yoğun & Hafif $=>2$ ile $<5$ & Sığ (20-49) \\
\hline Yalınkavak & 823 & 0.2 & Orta (6-11) & Çok yoğun & Orta $=>5$ ile $<10$ & Sığ (20-49) \\
\hline Yeniçağlar & 666 & 1.9 & Orta (6-11) & Yoğun & Orta $=>5$ ile $<10$ & Sığ (20-49) \\
\hline Kayabağı & 905 & 2.1 & Orta (6-11) & Çok yoğun & Hafif $=>2$ ile $<5$ & Sığ (20-49) \\
\hline Çarıklı & 552 & 0.2 & Orta (6-11) & Çok yoğun & Hafif $=>2$ ile $<5$ & Sığ (20-49) \\
\hline Yazıhan & 582 & 0.1 & Orta (6-11) & Yoğun & Hafif $=>2$ ile $<5$ & Sığ (20-49) \\
\hline Karpuzlu & 800 & 0.8 & Hafif (2-5) & Yoğun & Orta $=>5$ ile $<10$ & Sığ (20-49) \\
\hline Kavakdibi & 730 & 1.3 & Orta (6-11) & Yoğun & Hafif $=>2$ ile $<5$ & Sığ (20-49) \\
\hline Asmadere & 772 & 0.4 & Hafif (2-5) & Yoğun & Hafif $=>2$ ile $<5$ & Sığ (20-49) \\
\hline Yeşilova & 912 & 1.1 & Hafif (2-5) & Çok yoğun & Orta $=>5$ ile $<10$ & Sığ (20-49) \\
\hline Yapaklı & 763 & 0.8 & Orta (6-11) & Yoğun & Orta $=>5$ ile $<10$ & Sığ (20-49) \\
\hline Avcilar & 800 & 1.5 & Orta (6-11) & Çok yoğun & Hafif $=>2$ ile $<5$ & Sığ (20-49) \\
\hline Eskihamur & 584 & 1.1 & Orta (6-11) & Çok yoğun & Hafif $=>2$ ile $<5$ & Sığ (20-49) \\
\hline Merkez & 633 & 1.2 & Orta (6-11) & Çok yoğun & Orta $=>5$ ile $<10$ & Sığ (20-49) \\
\hline Balpınar & 532 & 0.8 & Orta (6-11) & Yoğun & Orta $=>5$ ile $<10$ & Sığ (20-49) \\
\hline Beyçayırı & 716 & 0.6 & Orta (6-11) & Çok yoğun & Orta $=>5$ ile $<10$ & Sığ (20-49) \\
\hline Uğurca & 558 & 1.1 & Hafif (2-5) & Çok yoğun & Hafif $=>2$ ile $<5$ & Sığ (20-49) \\
\hline Kuyubaşı & 715 & 1.2 & Hafif (2-5) & Yoğun & Hafif $=>2$ ile $<5$ & Sığ (20-49) \\
\hline Ulaşlı & 732 & 0.5 & Hafif (2-5) & Çok yoğun & Hafif $=>2$ ile $<5$ & Sığ (20-49) \\
\hline Kahveci & 652 & 0.8 & Hafif (2-5) & Yoğun & Orta $=>5$ ile $<10$ & Sığ (20-49) \\
\hline Yolağzı & 682 & 1.8 & Orta (6-11) & Çok yoğun & Hafif $=>2$ ile $<5$ & Sığ (20-49) \\
\hline Merkez & 526 & 2.0 & Orta (6-11) & Çok yoğun & Orta $=>5$ ile $<10$ & Sığ (20-49) \\
\hline Üçyol & 588 & 1.8 & Hafif (2-5) & Yoğun & Hafif $=>2$ ile $<5$ & Sığ (20-49) \\
\hline Deveboynu & 850 & 0.1 & Orta (6-11) & Yoğun & Orta $=>5$ ile $<10$ & Sığ (20-49) \\
\hline Gürbüs & 862 & 1.0 & Orta (6-11) & Çok yoğun & Orta $=>5$ ile $<10$ & Sığ (20-49) \\
\hline Arıkaya & 840 & 1.1 & Hafif (2-5) & Çok yoğun & Orta $=>5$ ile $<10$ & Sığ (20-49) \\
\hline Uzunçayır & 746 & 1.2 & Orta (6-11) & Çok yoğun & Orta $=>5$ ile $<10$ & Sığ (20-49) \\
\hline
\end{tabular}


Batman ili meralarının botanik kompozisyonunu belirlemek için Modifiye Edilmiş Tekerlekli Lup (halka) metodu kullanılarak 33 durakta vejetasyon etüdü yapılmıştır (Koç ve Çakal, 2004). Lup ölçümleri; her bir merada vejetasyon ve toprak açısından oldukça homojen olan ve her blokta merkez olarak kabul edilen bir noktadan itibaren noktalar arası mesafe $50 \mathrm{~cm}, 4$ ana yöneye (doğu, batı, kuzey ve güney) doğru uzanan $20 \mathrm{~m}^{\prime}$ lik 4 hat boyunca yapılmıştır. Her 20 m'lik hat üzerinde toplam 100 ve her blokta 400 olmak üzere bitki okuması yapılmıştır (Gökkuş ve ark. 2000). Bitki teşhisinde Davis (1970)'ten faydalanılmıştır. Okuma neticesinde tespit edilen bitki türleri azalıcılar, çoğalıcılar ve istilacılar olmak üzere 3 sınıfa ayrılmışlardır (Anonim, 2008). Tespit edilen bitkilerden azalıcıların tamamı, çoğalıcıların oranları ise \%20'si dikkate alınarak çalışılan meralarda "Mera Durumu" sınıflaması yapılmıştır (Alay ve ark. 2016; Uzun ve ark. 2016).

Okunan her bir bitki türüne ait değerler toplam bitki sayısına oranlanarak türlerin botanik kompozisyondaki oranları tespit edilmiştir. Mera kesimlerinde, bitki örtüsünün toprağı kaplama oranı vejetasyon etüdü sırasında bitkiye rastlanan nokta sayısının ölçülen toplam nokta sayısına oranlanması ile belirlenmiştir (Gökkuş ve ark., 2000). Mera durum sınıfı ve sağlığı sınıflamasının yapılmasında kullanılan değerler Çizelge 2'de sunulmuştur (Koç ve ark., 2003).

Çizelge 2. Mera durum sınıfı ve sağlığı değerlendirmesi Table 2. Rangeland condition and health table

\begin{tabular}{|c|c|c|c|}
\hline \multicolumn{2}{|c|}{ Mera durum sınıflaması } & \multicolumn{2}{|c|}{ Mera sağlığı sınıflaması } \\
\hline $\begin{array}{l}\text { Hesaba katılan } \\
\text { türlerin oranı } \\
(\%)\end{array}$ & $\begin{array}{l}\text { Durum } \\
\text { Sinıfı }\end{array}$ & $\begin{array}{l}\text { Toprağı } \\
\text { Kaplama } \\
\text { Oranı (\%)* }\end{array}$ & $\begin{array}{l}\text { Sağlık } \\
\text { Sınıfı }\end{array}$ \\
\hline $\begin{array}{l}\text { Pasture } \\
\text { condition } \\
\text { classification } \\
\text { proportion of } \\
\text { involved species } \\
(\%)\end{array}$ & $\begin{array}{l}\text { Condition } \\
\text { Class }\end{array}$ & $\begin{array}{l}\text { Pasture } \\
\text { health } \\
\text { classification } \\
\text { soil coverage } \\
\text { ratio (\%)* }\end{array}$ & Health class \\
\hline $76-100$ & Çok iyi & $>70$ & Sağlıklı \\
\hline $51-75$ & İyi & $55-70$ & Riskli \\
\hline $26-50$ & Orta & 55 & Sorunlu \\
\hline $0-25$ & Zayıf & & \\
\hline
\end{tabular}

*Modifiye edilmiş tekerlekli halka yöntemi verilerine göre uyarlanmıştır.

* Adapted according to the data obtained by Wheeled Ring Method

\section{Araştırma Bulguları ve Tartışma}

Batman'da 33 durakta yapılan vejetasyon etütlerinde 202 farklı tür tespit edilmiştir. Tespit edilen türlerin 52 tanesinin baklagil, 35 tanesinin buğdaygil ve 115 tanesinin de diğer familyalara ait türler olduğu belirlenmiştir. Bitki ile kaplı alanda baklagillerin kaplama oranı \%33.71, buğdaygillerin kaplama oranı \%27.27 ve diğer familya bitkilerininkaplama oranı ise $\% 39.02$ olarak hesaplanmıştır.

Vejetasyonda en fazla yer alan baklagiller; Astragalus hamosus (\%2.037), Medicago polymorpha (\%1.523), Medicago rigidula (\%6.981), Onobrychis caput-galli (\%2.000), Trifolium campestre (\%2.832), Trifolium cherleri (\%2.692), Trifolium nigrescens \%4.131) olurken, Poa bulbosa (\%3.308), Aegilops umbellulata (\%1.804), Avena sterilis (\%6.383), Bromus japonicus (\%1.103), Bromus tectorum (\%5.271) ve Hordeum murinum $(\% 1,505)$ en fazla rastlanılan buğdaygiller olmuştur. Vejetasyonda en fazla yer alan diğer familya türleri ise; Capsella bursapastoris (\%1.280),Bellis perennis (\%1.178), Crepis sancta (\%2.495), Erodium cicutarium (\%1.439), Eryngium campestre (\%1.561), Carduus pycnocephalus (\%3.019), Helianthemum ledifolium (\%1.196), Salvia multicaulis (\%1.065), Parentucellia latifolia (\%1.477), Sinapis arvensis (\%1.570), Biarum carduchorum (\%1.140) olarak belirlenmiştir (Çizelge 3 ve 4).

Belirlenen türlerin kalite derecelerine göre dağılımına bakıldığında; 13 tanesi çoğalıcı, 12 tanesi azalıcı ve 177 tanesi de istilacı türlerden oluştuğu görülmektedir (Şekil 2). Botanik kompozisyondaki çoğalıcıların oranı \%6.59, azalıcıların oranı \%3.15 ve istilacı türlerin oranı ise \%90.26 olarak tespit edilmiştir. Yurdumuzun değişik yörelerinde yapılan çalışmalarda da istilacı türlerin mera vejetasyonlarının çoğunluğunu oluşturduklarını ifade edilmiştir (Uzun ve ark., 2010;2015; Ünal ve ark., 2011; 2012a,b; 2013;2014; Yavuz ve ark., 2012; Çınar ve ark., 2014; Seydoşoğlu ve ark., 2015a,b). 


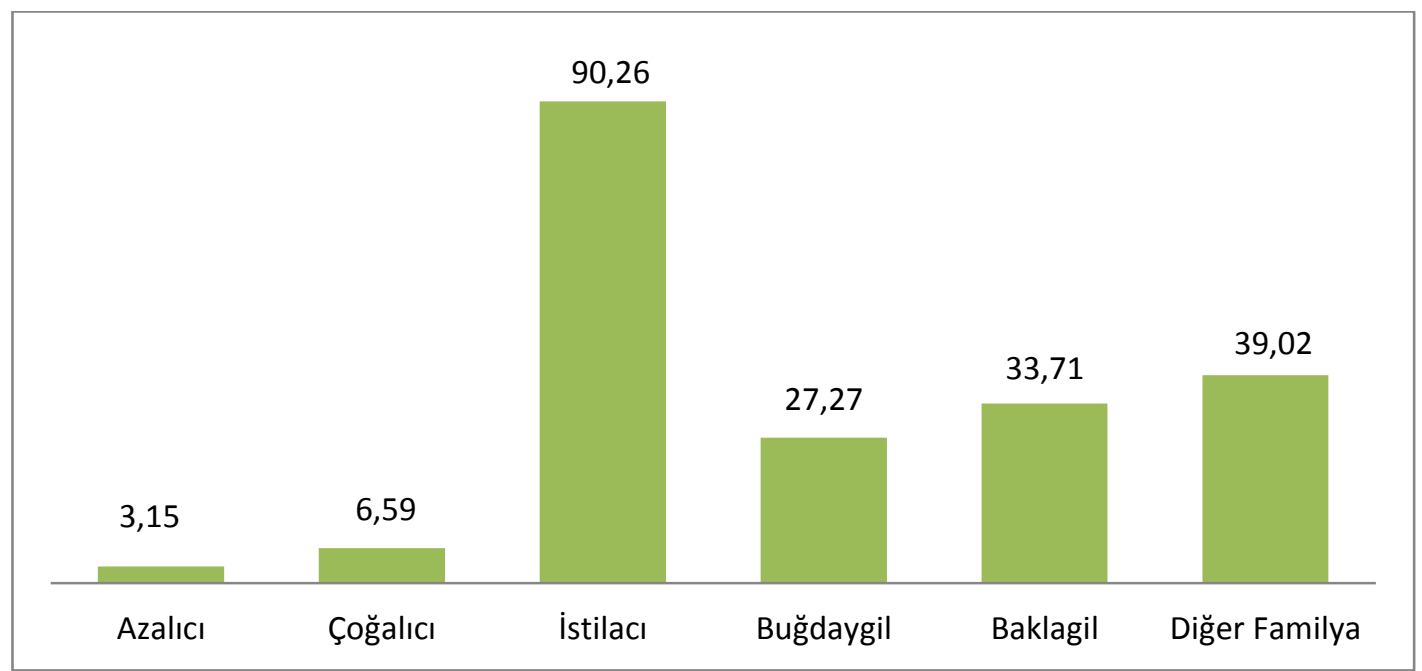

Şekil 2: Bitki ile kaplı alanda türlerin kalite derecelerine ve familyalarına göre kaplama oranları

Figure 2. Cover percentage of plant species depending on the quality grade and family in plant covered area

Çizelge 3. Azalıcı ve çoğalıcı türlerin toprağı kaplama (TKO) ve botanik kompozisyondaki oranları (BKO) (\%) Table 3. Foliar covers and ratios of decreaser and increaser plants in the botanical composition of rangelands (\%)

\begin{tabular}{lccccc}
\hline & $\begin{array}{c}\text { Çoğalıcılar } \\
\text { Increaser }\end{array}$ & & & & \multicolumn{2}{c}{$\begin{array}{c}\text { Azalıcılar } \\
\text { Decreaser }\end{array}$} \\
\hline Tür & TKO & BKO & Tür & TKO & BKO \\
\hline Andrachne telephioides & 0.053 & 0.065 & Chrysopogon gryllus & 0.129 & 0.159 \\
Coronilla scorpioides & 0.023 & 0.028 & Dactylis glomerata & 0.182 & 0.224 \\
Coronilla varia & 0.030 & 0.037 & Medicago sativa & 0.379 & 0.467 \\
Hordeum bulbosum & 0.167 & 0.206 & Trifolium pratense & 0.341 & 0.421 \\
Cynodon dactylon & 0.379 & 0.467 & Koeleria cristata & 0.023 & 0.028 \\
Festuca ovina & 0.303 & 0.374 & Lolium perenne & 0.333 & 0.411 \\
Stipa bromoides & 0.530 & 0.654 & Trifolium fragiferum & 0.227 & 0.280 \\
Poa supina & 0.114 & 0.140 & Bromus tomentellus & 0.189 & 0.234 \\
Poa bulbosa & 2.682 & 3.308 & Agropyron cristatum & 0.303 & 0.374 \\
Plantago atrata & 0.106 & 0.131 & Sanguisorba minor & 0.205 & 0.252 \\
Plantago lanceolata & 0.417 & 0.514 & Trifolium parviflorum & 0.091 & 0.112 \\
Plantago major & 0.030 & 0.037 & Onobrychis aequidentata & 0.152 & 0.187 \\
Teucrium polium & 0.508 & 0.626 & & 2.553 \\
\hline Toplam & 5.341 & 6.588 & & 3.150 \\
\hline
\end{tabular}

Azalıcı türler, klimaks bitki türleri olup hayvanların severek otladığı bol üretim gücüne sahip türlerdir. Botanik kompozisyondaki oranları itibariyle azalıcı türler sırasıyla; Medicago sativa (\%0.467), Trifolium pratense (\%0.421), Lolium perenne (\%0.411), Agropyron cristatum (\%0.374), Trifolium fragiferum (\%0.280), Sanguisorba minor (\%0.252), Bromus tomentellus (\%0.234), Dactylis glomerata (\%0.224), Onobrychis aequidentata (\%0.187), Chrysopogon gryllus (\%0.159), Trifolium parviflorum (\%0.112), Koeleria cristata $(\% 0.028)$, çoğalıcı türler sırasıyla Poa bulbosa (\%3.308), Stipa bromoides (\%0.654), Teucrium polium (\%0.626), Plantago lanceolata (\%0.514), Cynodon dactylon (\%0.467), Festuca ovina (\%0.374),
Hordeum bulbosum (\%0.206), Plantago atrata $(\% 0.131)$, Poa supina (\%0.140), Plantago major (\%0.037), Coronilla varia (\%0.004), Andrachne telephioides (\%0.065), Coronilla scorpioides (\%0.028) tespit edilmiştir (Çizelge 3). Çoğalıcı bitkiler ise, Meranın klimaks bitki örtüsünde çok az bulunan ve hayvanların otlamada isteksiz davrandığı türlerdir (Koç ve ark. 2003).

Hayvanların otlamadığı lezzetsiz, dikenli veya zehirli türler ile tek yıllık bitkilerin tamamı istilacı bitki olarak dikkate alınır (Koç ve ark. 2003). İstilacı türler, hayvanların otlatmadığı lezzetsiz, dikenli veya zehirli türler ile tek yıllık bitkilerin tamamı olan türlerdir. Botanik kompozisyondaki istilacı türler bakımından öne çıkanlar, Aegilops 
umbellulata (\%1.804), Capsella bursa-pastoris (\%1.208), Astragalus hamosus (\%2.037), Avena sterilis (\%6.383), Bellis perennis (\%1.178), Bromus japonicas (\%1.103), Bromus tectorum (\%5.271), Crepis sancta (\%2.495), Erodium cicutarium (\%1.439), Eryngium campestre (\%1.561), Carduus pycnocephalus (\%3.019), Trifolium nigrescens (\%4.131), Biarum carduchorum (\%1.140),
Helianthemum ledifolium (\%1.196) olarak belirlenmiştir (Çizelge 4). İstilacı türler içerisinde en düşük sınır \%1.103 olarak alınmıştır. Bitki türleri bakımından özellikle de istilacı türler, çoğu doğal meralarımız için büyük oranda benzerlik göstermektedir (Ünal ve ark., 2011;2012a.b; 2013;2014; Yavuz ve ark., 2012; Polat ve ark. 2018).

Çizelge 4.İstilacı Türlerin Toprağı Kaplama (TKO) ve Botanik Kompozisyondaki Oranları (BKO) (\%) Table 4. Foliar covers and ratios of invader plants in the botanical composition of rangelands (\%)

\begin{tabular}{|c|c|c|c|c|c|c|c|c|}
\hline \multicolumn{9}{|c|}{$\begin{array}{l}\text { İstilacılar } \\
\text { Invaders }\end{array}$} \\
\hline Tür & TKO & BKO & Tür & TKO & BKO & Tür & TKO & $\mathrm{BKO}$ \\
\hline Achillea aleppica & 0.023 & 0.028 & Hordeum murinum & 1.220 & 1.505 & Vicia sativa & 0.379 & 0.467 \\
\hline Actinolema macrolema & 0.053 & 0.065 & Hordeum spontaneum & 0.242 & 0.299 & Vulpia ciliata & 0.326 & 0.402 \\
\hline Aegilops cylindrica & 0.015 & 0.019 & $\begin{array}{l}\text { Hymenocarpus } \\
\text { circinnatus }\end{array}$ & 0.780 & 0.963 & Ziziphora capitata & 0.023 & 0.028 \\
\hline Aegilops triuncialis & 0.220 & 0.271 & Hypecoum imberbe & 0.303 & 0.374 & Vicia anatolica & 0.083 & 0.103 \\
\hline Aegilops umbellulata & 1.462 & 1.804 & Malva neglecta & 0.356 & 0.439 & Trifolium nigrescens & 3.348 & 4.131 \\
\hline Alopecurus myosuroides & 0.053 & 0.065 & Lagoecia cuminoides & 0.038 & 0.047 & Trifolium bullatum & 0.341 & 0.421 \\
\hline Anagallis arvensis & 0.129 & 0.159 & Lamium amplexicaule & 0.394 & 0.486 & $\begin{array}{l}\text { Tripleurospermum } \\
\text { parviflorum }\end{array}$ & 0.189 & 0.234 \\
\hline Anchusa azurea & 0.235 & 0.290 & Lathyrus cicera & 0.167 & 0.206 & Hypericum triquetrifolium & 0.053 & 0.065 \\
\hline Capsella bursa-pastoris & 1.038 & 1.280 & Linum hirsutum & 0.371 & 0.458 & Astragalus asterias & 0.326 & 0.402 \\
\hline $\begin{array}{l}\text { Anthemis } \\
\text { wiedemanniana }\end{array}$ & 0.076 & 0.093 & Linum mucronatum & 0.144 & 0.178 & Eminium rauwolffii & 0.265 & 0.327 \\
\hline Aristolochia bodamae & 0.045 & 0.056 & Linum strictum & 0.091 & 0.112 & Anthemis pseudocotula & 0.106 & 0.131 \\
\hline Astragalus aduncus & 0.159 & 0.196 & Lolium rigidum & 0.038 & 0.047 & Rostraria cristata & 0.167 & 0.206 \\
\hline $\begin{array}{l}\text { Astragalus } \\
\text { campylosema }\end{array}$ & 0.030 & 0.037 & Prosopis farcta & 0.136 & 0.168 & Echinaria capitata & 0.197 & 0.243 \\
\hline Astragalus hamosus & 1.652 & 2.037 & Ranunculus arvensis & 0.197 & 0.243 & Alopecurus utriculatus & 0.068 & 0.084 \\
\hline $\begin{array}{l}\text { Astragalus } \\
\text { microcephalus }\end{array}$ & 0.167 & 0.206 & Rhagadiolus angulosus & 0.091 & 0.112 & Trifolium echinatum & 0.038 & 0.047 \\
\hline Avena sterilis & 5.174 & 6.383 & Rumex pulcher & 0.182 & 0.224 & Scabiosa calocephala & 0.045 & 0.056 \\
\hline Bellis perennis & 0.955 & 1.178 & Salvia multicaulis & 0.864 & 1.065 & Rostraria cristata & 0.500 & 0.617 \\
\hline Bombycilaena erecta & 0.038 & 0.047 & Medicago minima & 0.061 & 0.075 & Cerastium glomeratum & 0.076 & 0.093 \\
\hline Bromus hordeaceus & 0.242 & 0.299 & Medicago polymorpha & 1.235 & 1.523 & Heteranthelium piliferum & 0.152 & 0.187 \\
\hline Bromus japonicus & 0.894 & 1.103 & Medicago radiata & 0.030 & 0.037 & Phlomis kurdica & 0.773 & 0.953 \\
\hline Bromus rubens & 0.053 & 0.065 & Medicago rigidula & 5.659 & 6.981 & Trigonella capitata & 0.136 & 0.168 \\
\hline Bromus scoparius & 0.220 & 0.271 & Moltkia coerulea & 0.106 & 0.131 & Lathyrus inconspicuus & 0.015 & 0.019 \\
\hline Bromus tectorum & 4.273 & 5.271 & Muscari comosum & 0.053 & 0.065 & Trigonella astroites & 0.038 & 0.047 \\
\hline Buglossoides incrassata & 0.023 & 0.028 & Muscari neglectum & 0.076 & 0.093 & Hedypnois cretica & 0.492 & 0.607 \\
\hline Crepis foetida & 0.053 & 0.065 & Neslia apiculata & 0.045 & 0.056 & Iris masia & 0.076 & 0.093 \\
\hline Crepis sancta & 2.023 & 2.495 & Notobasis syriaca & 0.583 & 0.720 & Vicia galeata & 0.318 & 0.393 \\
\hline Daphne glomerata & 0.030 & 0.037 & Onobrychis caput-galli & 1.621 & 2.000 & Picris kotschyi & 0.030 & 0.037 \\
\hline Echinaria capitata & 0.508 & 0.626 & Onobrychis crista-galli & 0.205 & 0.252 & Bunium paucifolium & 0.015 & 0.019 \\
\hline Echinops orientalis & 0.030 & 0.037 & Onosma microcarpum & 0.167 & 0.206 & Euphorbia haussknechtii & 0.053 & 0.065 \\
\hline Erodium cicutarium & 1.167 & 1.439 & Parentucellia latifolia & 1.197 & 1.477 & Convolvulus stachydifolius & 0.106 & 0.131 \\
\hline Erophila verna & 0.038 & 0.047 & Phlomis bruguieri & 0.477 & 0.589 & Anemone coronaria & 0.038 & 0.047 \\
\hline Eryngium campestre & 1.265 & 1.561 & Picnomon acarna & 0.106 & 0.131 & Gagea chlorantha & 0.023 & 0.028 \\
\hline Euphorbia macroclada & 0.030 & 0.037 & Plantago cretica & 0.439 & 0.542 & Gentiana olivieri & 0.015 & 0.019 \\
\hline Euphorbia orientalis & 0.121 & 0.150 & Scandix stellata & 0.205 & 0.252 & Ainsworthia trachycarpa & 0.136 & 0.168 \\
\hline Filago pyramidata & 0.114 & 0.140 & Senecio vernalis & 0.462 & 0.570 & Vicia lathyroides & 0.045 & 0.056 \\
\hline Gagea villosa & 0.106 & 0.131 & Sherardia arvensis & 0.030 & 0.037 & Biarum carduchorum & 0.924 & 1.140 \\
\hline Galium aparine & 0.015 & 0.019 & Sinapis arvensis & 1.273 & 1.570 & Eminium spiculatum & 0.417 & 0.514 \\
\hline Cardaria draba & 0.053 & 0.065 & Stellaria media & 0.530 & 0.654 & Micropus supinus & 0.023 & 0.028 \\
\hline Carduus pycnocephalus & 2.447 & 3.019 & $\begin{array}{l}\text { Taeniatherum caput- } \\
\text { medusae }\end{array}$ & 0.379 & 0.467 & Salvia palaestina & 0.091 & 0.112 \\
\hline Carthamus dentatus & 0.129 & 0.159 & Tamarix smyrnensis & 0.212 & 0.262 & Onosma albo-roseum & 0.129 & 0.159 \\
\hline
\end{tabular}

Çizelge 4.İstilacı türlerin toprağı kaplama (TKO) ve botanik kompozisyondaki oranları (BKO) (\%) (Devamı) 
Table 4. Foliar covers and ratios of invader plants in the botanical composition of rangelands (\%) (Continuation)

\begin{tabular}{|c|c|c|c|c|c|c|c|c|}
\hline \multicolumn{9}{|c|}{$\begin{array}{l}\text { İstilacılar } \\
\text { Invaders }\end{array}$} \\
\hline Tür & TKO & $\mathrm{BKO}$ & Tür & TKO & BKO & Tür & TKO & BKO \\
\hline Centaurea iberica & 0.235 & 0.290 & Taraxacum aleppicum & 0.242 & 0.299 & Lens orientalis & 0.038 & 0.047 \\
\hline Centaurium erythraea & 0.038 & 0.047 & Teucrium multicaule & 0.288 & 0.355 & Ranunculus macrorhynchus & 0.061 & 0.075 \\
\hline Ceratocephalus falcatus & 0.030 & 0.037 & Salvia viridis & 0.432 & 0.533 & Callipeltis cucullaria & 0.015 & 0.019 \\
\hline Chardinia orientalis & 0.242 & 0.299 & Torilis leptophylla & 0.447 & 0.551 & Ranunculus millefoliatus & 0.742 & 0.916 \\
\hline Cichorium intybus & 0.250 & 0.308 & Tragopogon longirostis & 0.023 & 0.028 & Alcea striata & 0.053 & 0.065 \\
\hline Gentiana lutea & 0.053 & 0.065 & Trifolium campestre & 2.295 & 2.832 & Carex pachystylis & 0.242 & 0.299 \\
\hline Geranium molle & 0.447 & 0.551 & Trifolium cherleri & 2.182 & 2.692 & Trifolium pauciflorum & 0.720 & 0.888 \\
\hline Geranium tuberosum & 0.068 & 0.084 & Trifolium hirtum & 0.091 & 0.112 & Vicia sericocarpa & 0.076 & 0.093 \\
\hline Gundelia tournefortii & 0.159 & 0.196 & Trifolium pilulare & 0.167 & 0.206 & Sclerochloa dura & 0.318 & 0.393 \\
\hline Helianthemum ledifolium & 0.970 & 1.196 & Trifolium purpureum & 0.076 & 0.093 & Gaudiniopsis macra & 0.053 & 0.065 \\
\hline Herniaria incana & 0.129 & 0.159 & Trifolium resupinatum & 0.068 & 0.084 & Nonea ventricosa & 0.061 & 0.075 \\
\hline Hippocrepis unisiliquosa & 0.068 & 0.084 & Trifolium scabrum & 0.439 & 0.542 & Trifolium bocconei & 0.129 & 0.159 \\
\hline Hirschfeldia incana & 0.068 & 0.084 & Trifolium spumosum & 0.439 & 0.542 & Trigonella spruneriana & 0.447 & 0.551 \\
\hline Holosteum umbellatum & 0.098 & 0.121 & Trifolium stellata & 0.114 & 0.140 & Vaccaria pyramidata & 0.038 & 0.047 \\
\hline Matricaria chamomilla & 0.167 & 0.206 & Trifolium stellatum & 0.689 & 0.850 & Valerianella vesicaria & 0.045 & 0.056 \\
\hline Geranium rotundifolium & 0.053 & 0.065 & Trifolium subterraneum & 0.795 & 0.981 & Verbascum lasianthum & 0.121 & 0.150 \\
\hline Anemone coronaria & 0.295 & 0.364 & Medicago lupulina & 0.379 & 0.467 & Vicia peregrina & 0.015 & 0.019 \\
\hline Ranunculus asiaticus & 0.462 & 0.570 & Trifolium tomentosum & 0.159 & 0.196 & Ornithogalum umbellatum & 0.030 & 0.037 \\
\hline Erysimum repandum & 0.053 & 0.065 & Trigonella monantha & 0.023 & 0.028 & Trigonella monspeliaca & 0.030 & 0.037 \\
\hline Genel toplam & & & & & & & 73.167 & 90.262 \\
\hline
\end{tabular}

Mera durum sınıflamasına göre, incelenen tüm meraların "zayıf" mera sınıfına girmektedir. Bu sonuca göre ülkemiz meralarının ortalamasına göre kötü durumdadır. Bunun nedeni otlatma yoğunluğu, uygun hayvan tipi ile otlatmama, otlatma mevsimine uyulmaması ve iklim faktörlerden kaynaklandığı söylenebilir. Türkiye'nin farklı yerlerinde yapılan meralarda da bizim meralarımıza benzerlik göstermiştir (Öztaş ve ark., 2003; Bilgen ve Özyiğit, 2005; Töngel ve Ayan, 2005; Çomaklı ve ark., 2012; Koç ve Kadıoğlu, 2012; Yavuz ve ark., 2012; Seydoşoğlu ve ark., 2015a,b).

Elde edilen veriler "mera sağlık sınıfı" açısından değerlendirildiğinde tüm meralar sağlıklı mera sınıfına dâhil olmuştur. Türkiye'nin farklı bölgelerinde yapılan çalışmalarda da genelde mera sağlık sınıfı açısından sağlıklı mera olduğu tespit etmişlerdir (Seydoşoğlu ve ark., 2015a.b; Alay ve ark., 2016).

Bitki ile kaplılık dereceleri bakımından; Yontukyazı \%82.00 Tepecik \%87.25, Değirmenüstü \%86.25, Ayrancı \%74.00, Akça \%74.25, Binatlı \%78.75, Oymataş \%73.50, Yalınkavak \%82.00, Yeniçağlar \%83.00,Kayabağı \%80.25, Çarıklı \%78.50, Yazıhan \%86.25, Karpuzlu \%86.25, Kavakdibi \%84.50, Asmadere \%91.50, Yeşilova \%85.75, Yapaklı \%79.00, Avcılar \%93.00,
Eskihamur \%76.50, Merkez-Beşiri \%90.00, Balpınar \%83.75, Beyçayırı \%86.25, Uğurca $\% 91.25$, Kuyubaşı \%83.75, Ulaşlı \%81.75, Kahveci \%79.25, Yolağzı \%90.50, Merkez-Hasankeyf \%79.00, Üçyol \%84.50, Deveboynu \%84.50, Gürbüs \%79.00, Arıkaya \%52.50, Uzunçayır \%47.50 olarak tespit edilmiştir. En yüksek bitki ile kaplı alan oranı \%93.00 ile Avcılar köyü merasında elde edilirken. en düşük oran ise $\% 47.50$ ile Uzunçayır köyü merasına ait olduğu belirlenmiştir. Ortalama bitki ile kaplı oran ise \%81.06 olarak tespit edilmiştir. Bitki ile kaplı alan oranları bulgularımız farklı bölgelerde yapılan çalışmalarla benzerlikler ve farklılıklar göstermektedir (Seydoşoğlu ve ark., 2015a,b; Alay ve ark., 2016; Uzun ve ark., 2016). Farklılığın nedeni, mera alanının büyüklüğü ve ekolojik koşullardan farklı olmasından kaynaklandığı söylenebilir.

\section{Sonuçlar}

Karasal iklimin hâkim olduğu Batman'da kış mevsimi serin ve yağışlı, yaz mevsimi ise sıcak ve kurak geçer. Batman ilinde yer alan meralar, sahil kuşağında bulunan meralara göre kuraklıkla birlikte otlatma baskısından daha fazla etkilenmekte ve mera vejetasyonları daha fazla zarar görmektedir. Mera durumu bakımından tüm 
meralar zayıf mera sınıfına dâhil olmuştur. Azalıcı ve çoğalıcı bitki oranlarının toplam \%9.74 olduğu merada yeniden tesis edilmeye ihtiyaç duymaktadır. Sağlık açısından ise iki mera (Uzunçayır ve Arıkaya) hariç diğer tüm meralara sağlıklı mera grubuna dâhil olmuştur. Zayıf mera alanları için, acilen mera alanları otlatılmaya kapatılmalıdır. Sonrasında yabancı ot savaşımı olmak üzere bazı bakım ve ıslah işlemlerinin uygulamaya konulması ve ayrıca uygulamaların da sık sık güncellemeleri gerekliliği göz önünde bulundurulmalıdır.

\section{Ekler}

Bu çalışma Bitkisel Üretim Genel Müdürlüğü (BÜGEM) tarafından desteklenen "Mera Varlığı ve Mera Durum Sınıflarının Belirlenmesi" adlı proje kapsamında yapılmıştır. Desteklerinden dolayı BÜGEM'e, teşekkürlerimizi sunarız. Ayrıca GAP Uluslararası Tarımsal Araştırma ve Eğitim Merkezi Müdürü Mehdi SÜMERLi'ye desteklerinden dolayı teşekkür ederiz.

\section{Kaynaklar}

Açıkgöz, E. (2001). Yem Bitkileri. Uludağ Üniversitesi Güçlendirme Vakfı Yayın No: 182, Bursa.

Alay, F., İspirli, K., Uzun, F., Çınar, S., Aydın, İ., \& Çankaya, N. (2016). Uzun süreli serbest otlatmanın doğal meralar üzerine etkileri. Gaziosmanpaşa Üniversitesi Ziraat Fakültesi Dergisi, 33(1): 116-124.

Anonim, (2005). Toprak ve arazi sınıflaması standartları teknik talimatı. http://www. tarim.gov.tr/Belgeler /Mevzuat/ Talimatlar/ Toprak Arazi Sınıflaması Standartları Teknik TalimativellgiliMevzuat_yeni.pdf [Erişim: 28.03.2018].

Anonim, (2008). Türkiye'nin Çayır ve Mera Bitkileri Kitabı. Tarım ve Köy işleri Bakanlığı, Tarımsal Üretim ve Geliştirme Genel Müdürlüğü. Çayır, Mera, Yem Bitkileri ve Havza Geliştirme Daire Başkanlığı. Ankara.

Anonim, (2018a). Türkiye İstatistik Kurumu. Tarım İstatistikleri. http://www.tuik.gov.tr/ UstMenu.do?metod =kategorist [Erişim: 06.03.2018].

Anonim, (2018b). Çevre ve Şehircilik Bakanlığı. Batman ili 2016 yılı çevre durum raporu. http://www.csb.gov.tr/db/ced/editordosya/BATMA N_icdr2016.pdf (Erişim tarihi: 04.05.2018).

Avağ, A., Mermer, A., Yıldız, H., Ünal, E., Urla, Ö., Aydoğdu, M., Dedeoğlu, F., Aydoğmuş, O., Torunlar, H., Tuğaç,
M.G., Ünal, S., Mutlu, Z., Özaydın, K.A., Özgöz, M.M., Aksakal, E., Kara, A., Uzun, M., Çakal, Ş., Yıldırım, T., Aksoyak, Ş., Tezel, M., Aygün, C., Kara, İ., Erdoğdu, I.., Sever, L., Atalay, A., Yavuz, T., Avcı M., Çınar, S., İnal, I.., Yücel, C., Cebel, H., Keçeci, M., Başkan, O., Depel, G., Palta, Ç., Çarkacı, A., Karadavut, U., Şimşek, U., Sürmen, M., Odabaşı, G., Gül, D., Koç, A., Erkovan, H.İ., Güllapoğlu, K., Kendir, H., \& Şahin, N. (2012). TUBITAK $106 \mathrm{G} 017$ nolu Ulusal Mera Kullanımı ve Yönetim Projesi Sonuç Raporu, Ankara.

Bilgen, M., \& Özyiğit, Y. (2005). Korkuteli ve Elmalı'da bulunan bazı doğal meraların vejetasyon durumlarının belirlenmesi. Akdeniz Üniversitesi Ziraat Fakültesi Dergisi, 18(2): 261-266.

Çınar, S., Hatipoğlu, R., Avcı, M., İnal, İ., Yücel, C., \& Avağ, A. (2014). Hatay ili Kırıkhan ilçesi taban meralarının vejetasyon yapısı üzerine bir araştırma. Gaziosmanpaşa Üniversitesi Ziraat Fakültesi Dergisi, 31(2): 52-60.

Çomaklı, B., Fayetörbay, D., \& Daşçı, M. (2012). Changing of botanical composition and canopy coverage ratio in rangelands at different altitudes. Atatürk Üniversitesi, Ziraat Fakültesi Dergisi, 43(1): 17-21.

Davis, P.H. (1970). Flora of Turkey and East Aegean Islands. Vol: 3, 518-531, University Press, UK: Edinburg.

Gür, M., \& Altın, M. (2015). Trakya Yöresinde Farklı Kullanım Geçmişine Sahip Meraların Florastik Kompozisyonlarının Bazı Özellikleri. Anadolu Tarım Bilimleri Dergisi. 30: 60-67.

Gökkuş, A., Koç, A., \& Çomaklı, B. (2000). Çayır-Mer'a Uygulama Kılavuzu. Atatürk Üniversitesi Ziraat Fakültesi. Yayın No:142, s:139, Erzurum.

Koç, A., Gökkuş, A., \& Altın, M. (2003). Mera durumu tespitınde dünyada yaygın olarak kullanılan yöntemlerin mukayesesi ve Türkiye için bır öneri. Türkiye 5. Tarla Bitkileri Kongresi, 13-17 Ekim, 36-42, Diyarbakır.

Koç, A., \& Çakal, Ş. (2004). Comparison of some rangeland canopy coverage methods. Int. Soil Congress on Natural Resource Management For Sustainable Development, June (7-10), 41-45, Erzurum.

Koç, A., \& Kadıoğlu, S., (2012). Some vegetation characteristics of an upland rangeland in Eastern Anatolia. Dry Grasslands of Europe: Grazing and Ecosystem Services Proceedings of 9th European Dry Grassland Meeting (EDGM), 19-23 May, 180-185, Prespa, Greece.

Öztaş, T., Koc, A., \& Comaklı, B. (2003). Changes in vegetation and soil properties along a slope on overgrazed and eroded rangelands. Journal of Arid Environments, 55: 93-100.

Seydoşoğlu, S., Saruhan, V., \& Mermer, A. (2015a). Diyarbakır ili Silvan ilçesi taban meralarının vejetasyon yapısı üzerinde bir araştırma. Türkiye Tarımsal Araştırmalar Dergisi, (2): 1-7. 
Seydoşoğlu, S., Saruhan, V., \& Mermer, A. (2015b). Diyarbakır ili Eğil ilçesi kıraç meralarının botanik kompozisyonunun belirlenmesi, Türkiye Tarımsal Araştırma Dergisi, (2): 76-82.

Polat, T., Budak, S., \& Akkaya, G. (2018). Adıyaman ili Kuyulu köyü doğal meralarının kuru ot verimi, kalitesi ve botanik kompozisyonu üzerine bir araştırma. Harran Tarım ve Gıda Bilimleri Dergisi. 22(3): 348-354. DOI: 10.29050/harranziraat.315709.

Töngel, M.Ö., \& Ayan, i̇. (2005). Samsun ili çayır ve meralarında yetişen bazı Zararlı bitkiler ve hayvanlar üzerindeki etkileri. OMÜ Ziraat Fakültesi Dergisi, 20(1): 84-93.

Uzun, F., Garipoğlu, A.V., \& Algan, D. (2010). Meralarımızda görülen sarı peygamber çiçeği (Centaurea solstitialis L.)'nin bitkisel özellikleri ve kontrolü. Anadolu Tarım Bilimleri Dergisi, 25(3): 213-222.

Uzun, F., Garipoğlu, A.V., \& Dönmez, H.B. (2015). Mera yabancı otlarının kontrolünde keçilerin kullanımı. Uluslararası Tarım ve Yaban Hayatı Bilimleri Dergisi, 1(1): 40-50.

Uzun, F., Alay, F., \& İspirli, K. (2016). Bartın ili meralarının bazı özellikleri. Türkiye Tarımsal Araştırmalar Dergisi. (3): 174-183.

Ünal, S., Karabudak, E., Öcal., M.B., \& Koç, A. (2011). Interpretations of vegetation changes of some villages rangelands in Çankırı province of Turkey.
Turkish Journal of Field Crops, 16(1): 39-47.

Ünal, S., Mutlu, Z., Mermer, A., Urla, Ö., Ünal, E., Aydoğdu, M., Dedeoğlu, F., Özaydın, K.A., Avağ, A., Aydoğmuş, O., Şahin, B., \& Aslan, S. (2012a). Ankara ili meralarının değerlendirilmesi üzerine bir çalışma. Tarla Bitkileri Merkez Araştırma Enstitüsü Dergisi, 21(2): 41-49.

Ünal, S., Mutlu, Z., Mermer, A., Urla, Ö., Ünal, E., Özaydın, K.A., Avağ, A., Yıldız, H., Aydoğmuş, O., Şahin, B., \& Aslan, S. (2012b). Çankırı ili meralarının mera durumu ve sağlığının belirlenmesi üzerine bir çalışma. Tarım Bilimleri Araştırma Dergisi, 5(2): 131135.

Ünal, S., Mutlu, Z., Urla, Ö., Yıldız, H., Şahin, B. (2013). Evaluation and determination of rangeland vegetation in Kayseri province. Tarla Bitkileri Merkez Araştırma Enstitüsü Dergisi, 22(2): 86-95.

Ünal, S., Mutlu, Z., Urla, Ö., Yıldız, H., Aydoğdu, M., Şahin, B., \& Aslan, S. (2014). Improvement possibilities and effects of vegetation subjected to long-term heavy grazing in the steppe rangelands of Sivas. Tarla Bitkileri Merkez Araştırma Enstitüsü Dergisi, 23(1): 22-30.

Yavuz, T., Sürmen, M., Töngel, M.Ö., Avağ, A., Özaydın, K., \& Yıldız, H. (2012). Amasya mera vejetasyonlarinin bazı özellikleri. Tarım Bilimleri Araştırma Dergisi, 5(1): 181-185. 